\title{
The Role of Competitive Activities on Preschool Children Performance
}

\author{
Angeliki A. Tsiakara, Nikolaos M. Digelidis \\ University of Thessaly, Department of Physical Education and Sport Science
}

\begin{abstract}
It is well recognized the importance of preschool children understanding of a product goal or a process goal in a school activity and in which way the kind of the goal could affect children's performance in this activity. As known, product goals determine the outcome of learning and lead students' attention to the outcome rather than to the strategy or method that can lead to the result. Instead, process goal refers to the methods and strategies that lead students learn handling a specific task. Herein, 30 preschool children (16 boys, 14 girls), at a mean age of $51 / 2$ years, participated in two different games, twice each with different goal each time (product goal/process goal). The results showed that preschool children exhibited better performance in both games when the goal was of product type. Moreover, in the case of a process goal, it was observed that children encouraged their classmate who played the game, while in case of a product goal they did not encourage their classmate, but they only counted his successful efforts. The results show that children understand the difference between process goal and product goal, enhancing their performance in case of product goals aiming to win. Nevertheless, previous studies which contacted in older children, under competitive learning environment where the goal of an activity emphasize to the outcome, showed that children brake their efforts, when and they feel that they cannot win. According the obtained results, preschool teachers should avoid the product goals and emphasize the process goals. Because the later consist the best possible strategy for helping preschool children to develop their skills, enhancing their performance in an activity and have positive educational experiences.
\end{abstract}

Keywords: education; childhood; competition; kindergarten; learning environment 